\title{
Questionário e pesquisa com usuário: reanálise da efetividade de questionário proposto para Trabalho de Conclusão de Curso em Design Editorial
}

Questionnaire and user research: reanalysis of the effectiveness of the proposed questionnaire for Course Completion Work in Editorial Design

Alexandre de Souza Ortolan Filho ${ }^{[1]}$, Lúcia Bergamaschi Costa Weymar ${ }^{[2]}$

\footnotetext{
Resumo: Este artigo é um recorte de uma pesquisa em design editorial e memória gráfica, mais precisamente, aqui se discorre sobre a criação, uso e análise de questionário para conhecimento de público-alvo. Durante a primeira análise para a realização de um produto editorial, fruto de uma pesquisa sobre nostalgia, percebeu-se que certas decisões poderiam ser aperfeiçoadas, sendo assim, viu-se necessário e pertinente uma discussão sobre a criação e aplicação de questionário. Será feita uma reanálise do questionário com a finalidade de criar um pensamento crítico sobre erros e acertos, propondo novas soluções.
}

Palavras-chave: Design editorial.Questionário.Usuário.Pesquisa. 
Abstract: This article is a research report on editorial design and graphic memory, more precisely, here if you find out about creating, using, and analyzing quizzes for public knowledge. During the first analysis for a product editorial, the result of research in editorial design and graphic memory, it was realized that certain auditions are considered perfect, so it was necessary and pertinent a discussion about the creation and application of questionnaire. A new analysis of the questionnaire will be made with the creation of critical thinking about errors and minutes, proposing new solutions.

Keywords: Editorial design.Questionnaire.User.Survey.

\section{INTRODUÇÃo}

Segundo Sampieri, Collado e Lucio (2013), existem vários motivos para a aplicação de um questionário, dentre eles a coleta de dados, por exemplo, que serve para a tomada de decisões. Ali (2009) afirma que a pesquisa de público-alvo para criação de produtos editoriais é muito comum e até mesmo necessária pois o conhecimento empírico do público é muito superficial e muda de acordo com os contextos sociais e temporais nos quais o entrevistado está inserido.

O questionário que serve de base para construção do presente artigo faz parte do Trabalho de Conclusão de Curso "Design e Nostalgia: Uma edição especial para a revista Recreio", realizado e apresentado em 2019 na Universidade Federal de Pelotas (UFPEL). O trabalho apresenta sólida explanação de conceitos metodológicos acerca dos principais aspectos estruturais da pesquisa, como os que se referem a construção, aplicação e análise de questionários. Contudo, ao longo da pesquisa identificamos certas carências e equívocos no questionário proposto e a possibilidade de uma série de melhorias é discutida neste artigo.

Dito isto, aprofundamos os conceitos que envolvem a construção de um questionário, necessários para o entendimento das oportunidades e, algumas vezes, das necessidades de sua aplicação. O questionário é um instrumento utilizado para a coleta de dados (SAMPIERI; COLLADO; LUCIO, 2013, p. 37) e basicamente segue uma linha lógica de execução: desenvolvimento, aplicação e análise. Este artigo concentra-se nesses três processos para maior compreensão e organização, sem esquecer de que se trata, especificamente, de um questionário na área de Design Editorial para aprofundamento de público-alvo. 


\section{DESENVOLVIMENTO}

\subsection{CONSTRUÇÃO}

Sampieri, Collado e Lucio (2013) mostram que a construção de um questionário já deve contar com um conhecimento prévio do contexto, afinal, não seria possível elaborar perguntas sem conhecer minimamente o provável respondente. E não apenas isso, devemos ter noção do tipo da pesquisa em que o questionário está inserido para buscar certa qualidade de resposta, ou seja, para definir entre respostas qualitativas e quantitativas.

Segundo Sampieri, Collado e Lucio (2013) a pesquisa quantitativa fornece dados que podem ser mensurados, como idade, renda, escolaridade, preferências, etc; em contrapartida, este tipo de pesquisa é ideal para compreender a percepção do participante em relação ao objeto estudado. 0 investigador que atua com pesquisa qualitativa tem o papel fundamental de interpretar as informações obtidas e relacioná-las e, para tal, deve-se ter conhecimento profundo do material em que a pesquisa se baseia.

\section{O pesquisador é o instrumento de coleta de dados em diversas técnicas desenvolvidas durante o estudo. [...] é o pesquisador que começa a aprender por meio da observação e descrição dos participantes e pensa em formas para registrar os dados (SAMPIERI; COLLADO; LUCIO, 2013, p. 37).}

No questionário construído para aquela pesquisa é proposta uma mescla de perguntas qualitativas e quantitativas, mais precisamente três perguntas abertas (qualitativas) e dezesseis perguntas fechadas (quantitativas). Como se pode observar, a proporção de perguntas abertas e fechadas é desigual, e isso ocorre pela facilidade de coletar dados predispostos, já que existem ferramentas bastante completas para ajudar na análise dos dados. Em contrapartida, dados qualitativos são mais complexos e exigem maior tempo para se- 
rem analisados. Podemos observar, então, a primeira chance de aprimoramento daquele questionário uma vez que as perguntas qualitativas não foram pensadas levando em consideração o processo de análise. Uma pergunta pertinente à pesquisa não necessariamente será a mais adequada; isso ocorre porque, mesmo havendo uma sequência de execução em um questionário, ele deve ser pensado como um conjunto. Sendo assim, é necessário se pensar na aplicação e análise na sequência de sua construção (SAMPIERI; COLLADO; LUCIO, 2013).

A seguir apresentamos as questões de caráter qualitativo presentes no questionário e, na continuação, uma breve discussão da efetividade de cada questão.

\subsubsection{Questão Qualitativa 1: Por gentileza, agora descreva o que você sentiu ao ver essas imagens da revista. 0 que você acha que deu origem a estes sentimentos?}

Após a exposição do objeto sobre o qual o questionário se baseia (Revista Recreio) perguntamos sobre o sentimento pessoal do respondente, o que a configura como uma pergunta dupla. Embora tenhamos atingido o objetivo da questão, isto é, identificar a presença do sentimento nostálgico percebemos na análise das respostas, ainda assim, discrepância na interpretação e isso se dá pela segunda metade da questão que deixa margem muito grande para interpretações e respostas divergentes. Como solução, poderíamos ter descartado a segunda metade da questão, pois o objetivo já havia sido alcançado na primeira metade.

\subsubsection{Questão Qualitativa 2:Como foi seu último contato com a revista?}

Esta talvez tenha sido a questão mais problemática apresentada no questionário, pois a característica de ser aberta deixa margem gigantesca a interpretações e, até mesmo, a respostas. Na análise da questão percebemos uma dificuldade muito grande para traçar perfis de respondentes, técnica apresentada por Sampieri, Collado e Lucio (2013), a ser contemplada, a seguir, na seção "Análise". Deste modo, traçamos muitos per- 
fis sendo necessário, inclusive, o acréscimo do perfil "outros" uma vez que não conseguimos enquadrar certas respostas. Como solução poderia ter sido viável especificar a qual contato a pergunta se referia; deste modo, seria possível transformar as respostas em dados numéricos, o que facilitaria a análise.

\subsubsection{Questão Qualitativa 3:Por fim, você gostaria de compartilhar mais alguma lembrança, sentimento ou informação em relação à Revista Recreio?}

Embora possa ser considerada muito aberta e com uma infinidade de possíveis respostas esta questão, em específico, acaba servindo de validação para a pesquisa. As respostas permitem a aproximação do público uma vez que percebemos o entusiasmo dos respondentes com o questionário e com o objeto em si já que a resposta, não sendo obrigatória, é respondida pela maioria dos participantes.

Podemos afirmar que a construção de um questionário está diretamente ligada a sua análise. O pensamento prévio de como se dará a análise das questões não só ajuda em sua organização como também proporciona maior qualidade de respostas.

Em relação às perguntas quantitativas não é necessário a correção ou adaptação da maior parte; contudo, há uma questão específica que merece ser analisada e que pode ser observada na figura 01.

Na sua opinião, qual a relevância dos elementos visuais citados abaixo na composição da revista?

Figura 01: Pergunta quantitativa/ escala. Fonte: Elaborado pelo autor (2019).

Marque 1 para: nenhuma relevância; 5 para: muito relevante

Logotipo *

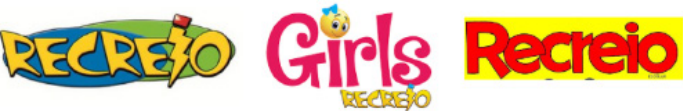


O questionário conta com uma série de perguntas, em escala, referentes a aspectos gráficos encontrados no objeto de análise. Em um primeiro momento almejamos que tais perguntas serviriam de respaldo para a tomada de decisões no projeto proposto; todavia, a seleção dos elementos contemplados parte de uma pré-seleção pessoal do autor que seleciona os elementos gráficos de acordo com o seu conhecimento. Sendo assim, há pouca variação entre um item e outro sendo que em sua maioria apresenta a resposta "muito relevante". Por um lado, confirmamos que os aspectos gráficos escolhidos são de fato relevantes; por outro lado, não percebemos claramente o grau de importância de tais itens.

\subsection{APLICAÇÃO}

De acordo com Ali (2009) cada pesquisa exige diferentes coletas de dados. A autora parte da pesquisa de reconhecimento e aprofundamento do usuário final de certo produto editorial; sendo assim, expõe alguns dos métodos de coleta de dados.

\subsubsection{Entrevistas pessoais}

Método muito confiável porque ocorre a verificação simultânea dos dados e o contato mais íntimo com o público. Entretanto, essa modalidade de pesquisa nem sempre é viável na medida em que é preciso muito mais tempo para ser realizada e, consequentemente, acaba tendo abrangência mais limitada.

\subsubsection{Entrevistas por telefone}

Meio de entrevista direta com possibilidade de correção e implementação de dados de modo verossímil. Ainda sim, este tipo de entrevista requer tempo e uma base de participantes a serem entrevistados; normalmente usam-se os dados obtidos no momento da assinatura do periódico pelo usuário. 


\subsubsection{Mala-direta}

Questionário enviado pelo correio; normalmente é um método mais demorado do que as outras opções por depender do prazo estipulado pelos correios.

\subsubsection{Questionário}

Último processo contemplado por Ali (2009) e o escolhemos para a coleta de dados do público-alvo da revista Recreio. Para a pesquisa em questão criamos um formulário online através da plataforma Google Docs e o divulgamos através da rede social Facebook, como se pode observar na figura 02.

Alexandre Souza compartilhou um link.

13 de maio

Olá, meu nome Alexandre, sou graduando do curso de Design Gráfico e estou realizando o meu TCC.

Este questionário faz parte da pesquisa e se você já foi leitor da revista RECREIO sinta-se a vontade para participar. Sua participação é muito IMPORTANTE e não leva nem 10 minutos para responder tudo. Você ainda pode receber o resultado da pesquisa em seu e-mail. Obrigado pela atenção $: \cdot$

Link:

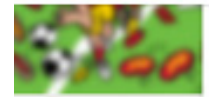

\section{Design Editorial e Revista Recreio}

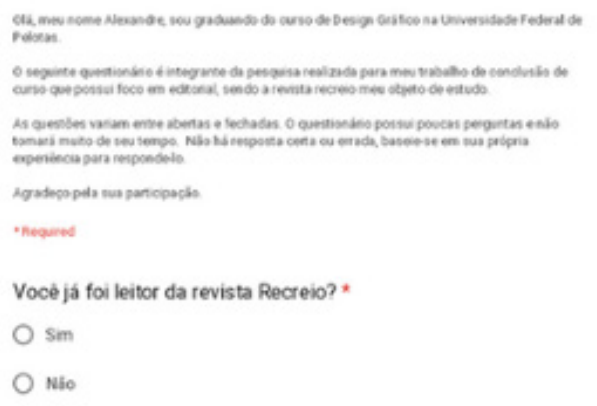

DOCS.GOOGLE.COM

\section{Design Editorial e Revista Recreio}

Olá, meu nome Alexandre, sou graduando do curso de Design Gráfico na.
Figura 02: Post no grupo UFPEL, na rede Facebook, 2019. Fonte: Elaborado pelo autor (2019). 
É importante salientar que tanto em relação ao convite para a realização do questionário quanto para a possível escrita de sua introdução é necessária uma linguagem que esteja em conformidade com o público proposto, que seja de fácil interpretação e de tamanho reduzido. Sampieri, Collado e Lucio (2013) afirmam que não se deve entregar todas as intenções da pesquisa pois, assim, poderíamos estar interferindo na resposta dos participantes. No questionário em questão pretendíamos verificar o sentimento nostálgico acerca do objeto estudado; assim, usar a palavra "nostalgia" poderia servir de coação para que a mesma fosse utilizada pelos respondentes. Por essa razão tal palavra não foi utilizada em nenhuma parte da coleta de dados, nem na sua divulgação e nem no texto introdutório que acompanha o questionário. Foi possível, então, observar um resultado mais fidedigno no qual a palavra nostalgia é observada em mais de $80 \%$ das respostas. Tal ocultação de informação pode ser traduzida para diversas questões relacionadas ao resultado almejado.

Outro fator importante a ser levado em consideração na aplicação do questionário é o local onde será divulgado. A definição se dá pelo conhecimento prévio do público-alvo. Por exemplo, uma divulgação online para um público mais idoso nem sempre será a melhor alternativa. Para a divulgação do questionário analisado realizamos duas postagens na rede social Facebook, uma no perfil pessoal do autor e a outra no grupo UFPEL. A escolha dos locais se dá por dois motivos: conveniência e oportunidade. Escolher o meio de aplicação por conveniência pode parecer uma manipulação, mas, segundo Ali (2009), esse meio é válido e, em certas situações, até necessário. No caso específico desta pesquisa o tempo é agente determinante para a escolha do local de divulgação e a plataforma Facebook é grande disseminadora de informação através do compartiIhamento, uma vez que observamos que o autor e o grupo da UFPEL partilhavam de contatos em comum, jovens que seriam o público almejado. Pelo número de respondentes, ao todo 221, confirmamos a efetividade do local de divulgação escolhido. 


\subsection{ANÁLISE}

A análise dos dados coletados vai depender dos aspectos quantitativos e qualitativos presentes. Para dados quantitativos, o modo mais comum de apresentação é por meio de gráficos. É importante ser claro na apresentação da informação; assim, escolher o melhor gráfico para cada situação ajuda o leitor e até mesmo o pesquisador a compreender os dados. Podemos ver, na imagem abaixo (Fig. 03), um exemplo de gráfico utilizado em respostas quantitativas e os motivos que resultaram na sua escolha.

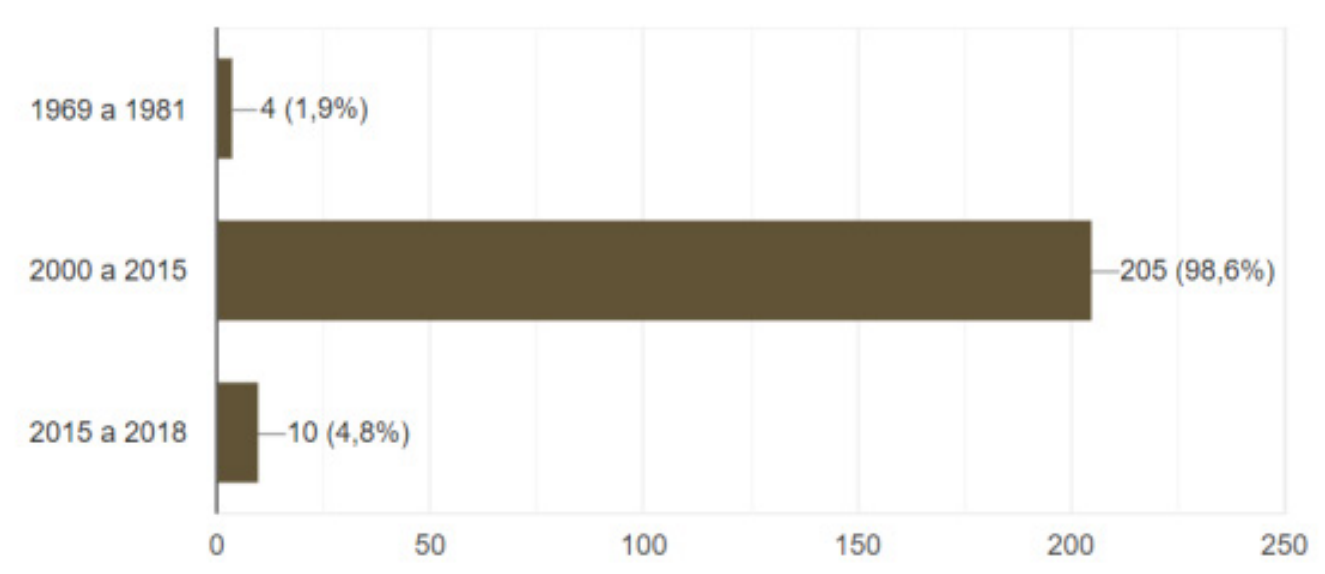

Figura 03: Respostas advindas de pergunta quantitativa apresentada em gráfico, 2019. Fonte: Elaborado pelo autor (2019).

No gráfico acima é possível observar que informações simples tendem a ser expostas também de forma simples. O gráfico de barras horizontais é o suficiente nessa situação pois apresenta de modo claro as informações mais relevantes e se encaixa melhor em documento no formato A4 comparado a um gráfico vertical que ocuparia mais espaço no mesmo formato de documento. Outros tipos de gráficos também conseguem traduzir as mesmas informações como, por exemplo, um gráfico de pizza; contudo, é sempre melhor optar pela simplificação (SAMPIERI; COLLADO; LUCIO, 2013). 
Perguntas qualitativas são mais difíceis de serem mensuradas em gráficos pois não possuem informações predispostas; Sampieri, Collado e Lucio (2013) mostram algumas alternativas para estudar e apresentar esses tipos de dados. Primeiramente, é preciso identificar a necessidade de análise e apresentação. Nem sempre todos os dados são importantes para o leitor e não precisam, então, ser apresentados de modo muito elaborado. Um exemplo é a "Pergunta Qualitativa 03". A pergunta e as respostas coletadas são de grande proveito para o pesquisador que pode interpretar e expor os resultados em um texto e de modo superficial. Outras perguntas qualitativas são cabíveis de maior visibilidade para o leitor; sendo assim, é realizado uma conversão na qualidade das respostas que tenta traduzi-las em perfis de respondentes o que facilita a criação de gráficos.

A figura 04, referente à "Pergunta Qualitativa 01", é um exemplo de como realizar transposição de respostas abertas em dados quantitativos. O processo envolve a coleta e análise das respostas buscando padrões. Uma vez encontrados, normalmente pelo mesmo uso de palavras-chave, criam-se categorias onde são encaixadas todas as respostas e, posteriormente, aplicadas em um gráfico. Nele podemos perceber que não houve muita divergência nas respostas obtidas, fato que resultou em um gráfico bastante simples.

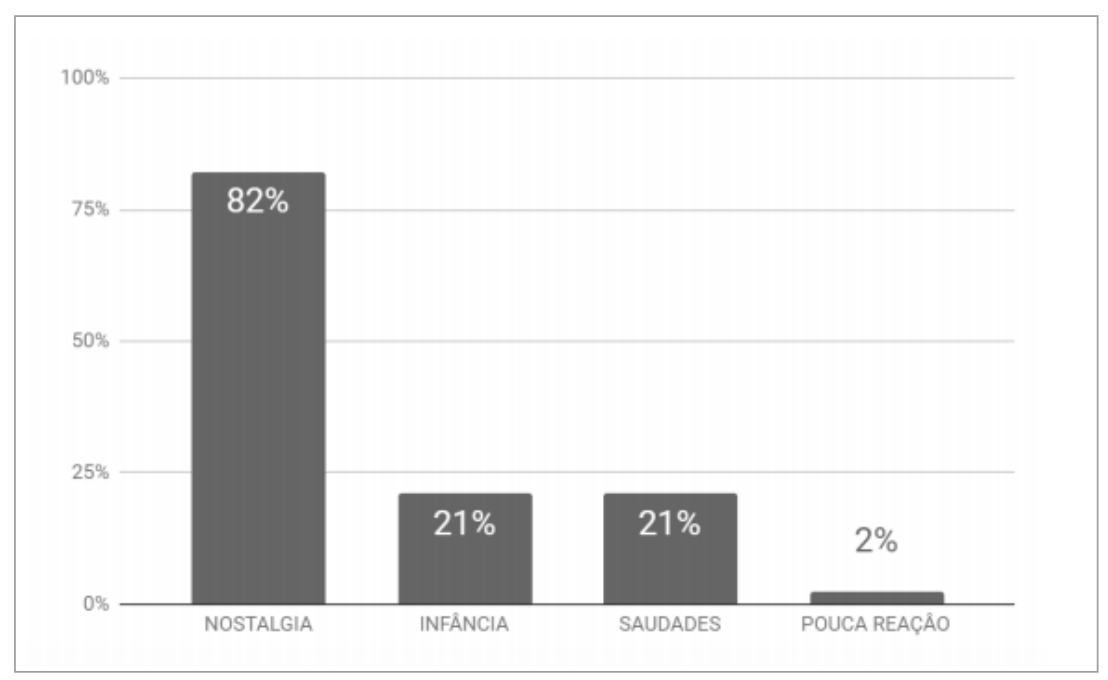

Figura 04: Respostas qualitativas apresentadas em gráfico no questionário analisado, 2019. Fonte: Elaborado pelo autor (2019). 
No mesmo questionário, entretanto, podemos observar um exemplo de transposição confusa e pouco eficiente para a apresentação dos dados qualitativos; trata-se do gráfico resultante (Fig. 05) da "Pergunta Qualitativa 02".

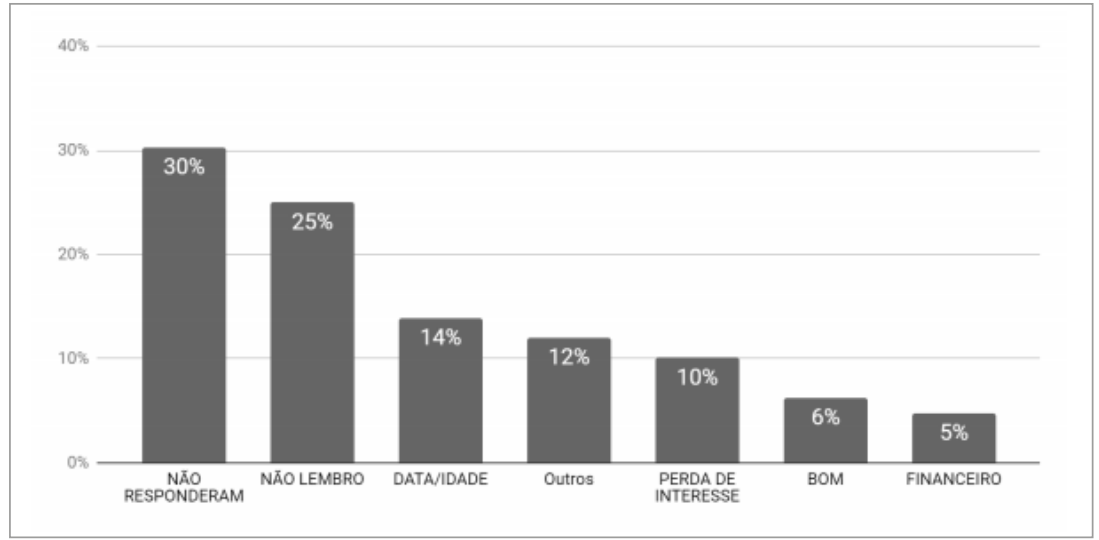

A figura acima apresenta um exemplo confuso de dados qualitativos representados em um gráfico. Primeiramente, pelo número de categorias, o que deixa aparente a grande divergência de respostas e interpretações. Ao analisar as categorias também notamos pouca coesão o que deixa o gráfico confuso e, até mesmo, questionável. Uma solução seria a apresentação dos resultados através de texto, pois assim a informação estaria mais clara.

\section{CONCLUSÃO}

Após a reanálise do questionário original observamos alguns pontos que podem ser aprimorados, como a apresentação de resultados, a tradução dos resultados qualitativos em gráfico e a construção de perguntas. As possibilidades de adequação seguem sendo as sugeridas em cada tópico.

Embora tenhamos verificado algumas deficiências no questionário analisado, concluímos que o mesmo tem grande valor para a aproximação do autor com o público-alvo e para tomada de decisões durante a pesquisa qualificando-se como um método de coleta de dados bastante satisfatório.
Figura 05: Respostas qualitativas apresentadas em gráfico no questionário analisado, 2019. Fonte: Elaborado pelo autor (2019). 
No que compete à divulgação do questionário chegamos à conclusão, legitimada pelo expressivo número de respondentes e pelas respostas qualificadas, que os métodos utilizados são eficientes. Dito isto, não recomendamos possíveis métodos alternativos, neste caso.

Em relação aos pontos contemplados neste artigo declaramos que a reanálise se dá por concluída e é de grande contribuição para futuras pesquisas que envolvam questionário e pesquisa de público-alvo/usuário.

\section{REFERÊNCIAS BIBLIOGRÁFICAS}

ALI, Fátima. A arte de editar revistas. São Paulo:

Companhia Editora Nacional, 2009. p. 399.

SAMPIERI, Roberto Hernández; COLLADO, Carlos

Fernández; LUCIO, María Del Pilar Baptista. Metodologia

da Pesquisa. Porto Alegre: Penso Editora, 2013. p. 624. 